\title{
Dry-Powder of Chitosan-Coated Lipid-Core Nanocapsules Containing Dapsone: Development, Laser diffraction Characterization and Analytical Quantification
}

\author{
Rodrigo Cé ${ }^{\mathrm{a}^{*}}$, Denise Soledade Jornada ${ }^{\mathrm{a}}$, João Guilherme Barreto De Marchi ${ }^{\mathrm{a}}$, Silvia Stanisçuaski Guterres ${ }^{\text {a }}$ and Adriana \\ Raffin Pohlmann ${ }^{\mathrm{a}, \mathrm{b}}$. \\ ${ }^{a}$ Programa de Pós-Graduação em Ciências Farmacêuticas, Faculdade de Farmácia, Universidade Federal do Rio Grande do \\ Sul, Porto Alegre, RS, Brazil. \\ ${ }^{b}$ Departamento de Química Orgânica, Instituto de Química, Universidade Federal do Rio Grande do Sul, Porto Alegre, RS, \\ Brazil. \\ *Corresponding author: rodrigoce_@hotmail.com
}

\begin{abstract}
Analytical techniques are critical for ensuring physical and chemical stability of a drug both for assessing the stability of drug molecules and for quantifying and identifying the drug content in products. We proposed the development of dry-powders of lipid-core nanocapsules containing dapsone and coated with chitosan, as well as, the analytical quantification of dapsone in drypowders with $1 \%$ and $2 \%(\mathrm{w} / \mathrm{v})$ of leucine by high-performance liquid chromatography (HPLC). Size is the most relevant physicochemical property of nanoparticulated drug delivery systems. In this context, our results demonstrated that during the powders redispersion in water, could be observed that the mean particle diameters (DAP-LNC-CS-L1 and DAP-LNC-CS-L2) decreased with redispersion times increase. The spray-drying of the lipid-core nanocapsule formulations showed yields ranging from $58 \pm 1.0 \%$ (DAP-LNC-CS-L1) to $61 \pm 1.5 \%$ (DAP-LNC-CS-L2) indicating an efficient drying process. In this context, the analytical quantifications of dapsone in the dry powders of nanocapsules by HPLC showed that the dapsone content ranged from $92 \pm 1.4 \%$ (DAP-LNC-CS-L2) to $95 \pm 0.8 \%$ (DAP-LNC-CS-L1). Can be concluded that spray-drying process of DAPLNC-CS-L1 and DAP-LNC-CS-L2 formulations showed an efficient aqueous dispersion of nanocapsule powders and the analytical quantification of dapsone in spray-dryed powders were higher than $90 \%$.
\end{abstract}

Keywords: Dapsone; chitosan; lipid-core nanocapsules; dry-powder, analytical quantification.

\section{Introduction}

Dapsone (fig. 1) is a sulfone that has dual action mechanisms, as antimicrobial and anti-inflammatory (1). After oral administration, dapsone can be almost completely absorbed by intestine and has a bioavailability higher than $86 \%(2,3)$. The main adverse effects, caused by its use, are methemoglobinemia, agranulocytosis and hemolytic anemia (4). However, the antiprotozoal effect of dapsone can be used for prophylaxis and prevention of recurrence in AIDS patients with pneumocystis jiroveci pneumonia and toxoplasmosis $(1,3)$.

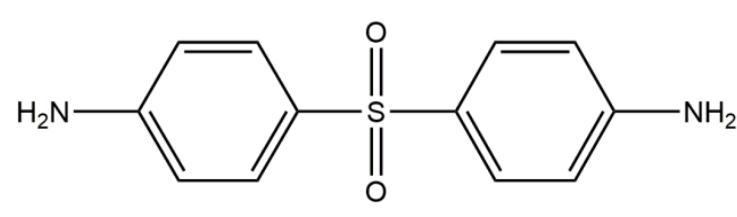

Figure 1: Molecular structure of dapsone

Chitosan is a biocompatible and biodegradable biopolymer that provides a cationic charge when dissolved in acetic acid (5). Due to its physicochemical properties, chitosan is used as carrier for various drugs and for controlled release applications. The potential of chitosan has been explored for oral and nasal administration of polar drugs due to their bioactivities. Chitosan associated with drug-containing formulations may exhibit dual therapeutic effects (6).
The spray-drying technique is being increasingly applied to dry aqueous or organic suspensions and emulsions for food, chemical, pharmaceutical and biopharmaceutical industries. In the pharmaceutical industry spray-drying technique can be used to produce particle powders that can be administered by the pulmonary, nasal and oral routes $(7,8)$. The drying process consists of a complex system in which several parameters can influence final product characteristics, however, studies of pre-formulation preparation are necessary to obtain products with adequate characteristics $(9,10)$.

In pharmaceutical research field, drugs analytical research, drug formulations, degradation products and impurities, and biological samples containing drugs is very important and necessary to analytical investigation. Analytical techniques are critical for ensuring the physical and chemical stability of drugs, for assessing the stability of drug molecules, for identifying and quantifying the drug content in the products $(11,12)$. In the 1980s, HPLC methods first appeared for the pharmaceutical assay (united states pharmacopoeia, 1980) (13). High performance liquid chromatography (HPLC) is one of the most widely used techniques for analysis of drugs and formulations. In liquid chromatography, the selection of the detection method is critical to ensure that all components are detected $(11,12)$.

Our research group has been studying the use of spraydrying technique to dry aqueous dispersions of polymer nanoparticles (14-16). The use of drying adjuvants such as silicon dioxide (17), manitol, hydroxypropylmethylcellulose (HPMC) (18) and leucine (19) is necessary to form microaggregate containing the polymer nanoparticles during 
the process. In this way, we proposed the development of dry-powders of lipid-core nanocapsules containing dapsone and coated with chitosan assaying $1 \%$ and $2 \%(\mathrm{w} / \mathrm{v})$ of leucine as drying adjuvant, as well as the detection of the analytical quantification of dapsone in dry-powders by HPLC. Each step of the study is represented in Figure 2.

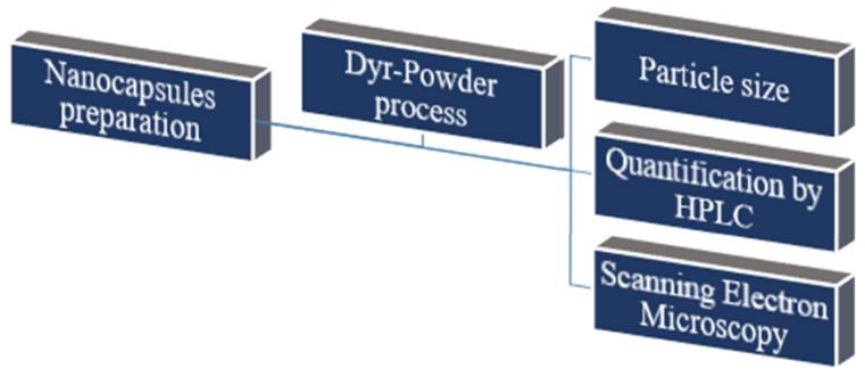

Figure 2: Schematic representation of the present study.

\section{Experimental}

\section{Materials}

Poly(ع-caprolactone) (PCL) (Mn $10 \mathrm{~kg} \mathrm{~mol}^{-1}$, Mw $14 \mathrm{~kg}$ $\mathrm{mol}^{-1}$ ), chitosan low molecular weight (Mw 50-190 kg $\mathrm{mol}^{-1}$ ) and sorbitan monostearate (Span 60®) were obtained from Sigma-Aldrich (USA). Lipoid ${ }^{\circledR}$ S75 (lecithin 75\%) was purchased from Gerbras (Brazil). Polysorbate 80 and caprylic/capric triglyceride were acquired from Delaware (Brazil). Dapsone was obtained from DEG (Brazil). The chemicals and solvents used in this study were of analytical grade.

\section{Methods}

Preparation of the chitosan-coated dapsone-loaded lipidcore nanocapsules

The chitosan-coated dapsone-loaded lipid-core nanocapsules (DAP-LNC-CS) were prepared following the selfassembling method as previously described by Cé et al., 2016 (20). Thus, to obtain the DAP-LNC-CS suspension an organic phase containing sorbitan monostearate $(0.040 \mathrm{~g})$, caprylic/capric triglyceride $(0.120 \mathrm{~g})$ poly( $\varepsilon$-caprolactone) $(0.100 \mathrm{~g})$ and dapsone $(0.010 \mathrm{~g})$ were dissolved in acetone $(30 \mathrm{~mL})$ at $40{ }^{\circ} \mathrm{C}$. In addition, a solution containing Lipoid ${ }^{\circledR}$ S75 (0.06 g) was prepared and solubilized in ethanol (4 mL) and poured into the acetone solution. The organic phase was then injected into an aqueous solution $(60 \mathrm{~mL})$ containing polysorbate $80(0.08 \mathrm{~g})$ using a funnel. All organic solvents were removed from the suspension by rotary evaporator under reduced pressure at $40{ }^{\circ} \mathrm{C}$ to $9 \mathrm{~mL}$. The suspension $(9$ $\mathrm{mL}$ ) was coated after an interfacial reaction with chitosan by adding $1 \mathrm{~mL}$ of $1 \%(\mathrm{w} / \mathrm{v})$ chitosan solution. This reaction was kept under magnetic stirring for 4 hours at room temperature. The DAP-LNC-CS suspension was characterized by laser diffraction, dynamic light scattering, potentiometry, zeta potential and HPLC, as previously reported (20).

\section{Spray-Drying of DAP-LNC-CS dispersion}

Prior the drying the final volume of the DAP-LNC-CS suspension was adjusted to $50 \mathrm{~mL}$. For formulations drying, $1 \%$ or $2 \%(\mathrm{w} / \mathrm{v})$ of a leucine solution was added, and the mixture was fed into a Mini Spray-Dryer (Buchi, B-290, Switzerland) following the parameters: inlet temperature $\left(120{ }^{\circ} \mathrm{C}\right)$, outlet temperature $\left(60^{\circ} \mathrm{C}\right)$, Pump $15 \%$, Nozzle 1 and aspirator at $100 \%$. After drying process, the formulation powders were removed from collection flask and stored in a vacuum desiccator. The formulation spray-dried powders were prepared in triplicate and renamed by DAP-LNC-CSL1 (1\% leucine) and DAP-LNC-CS-L2 (2\% leucine).

\section{Characterization of the nanocapsule spray-dried powder}

The yields $(\%)$ of spray-dried powders were calculated on the ratio between the sum of the weights of all solid components and experimentally obtained solid mass. To determine the water content, $1 \mathrm{~g}$ of the samples were added in an infrared moisture analyzer (Ohaus MB45, USA) and evaluated at $105{ }^{\circ} \mathrm{C}$ for 1 minute. The diameter profiles of powders formulations after dispersion in water was evaluated using laser diffraction technique (Mastersizer 2000, Malvern, UK). The powders were inserted in the wet dispersion unit of the instrument $(2000 \mathrm{rpm})$ and data were recorded in predetermined time intervals (every 5 minutes) from 0 to 30 minutes (Mastersizer ${ }^{\circledR}$ 2000, Hydro SM). All measurements were performed in triplicate.

\section{Analytical Quantification of Dapsone in Spray-Powders}

The powders $(12 \mathrm{mg})$ of the DAP-LNC-CS-L1 or DAPLNC-CS-L2 formulations were dispersed in a $10 \mathrm{ml}$ volumetric flask containing a mixture of acetonitrile/water/acetic acid (40:59:1, v/v/v). Subsequently, the samples were extracted for 30 minutes in sonicator at room temperature and filtered $(0.45 \mathrm{Mm}$, Millipore) for quantification by High Performance Liquid Chromatography (HPLC) (Shimadzu LC-20A system, CBM-20A system controller, SPD-M20A photodiode-array detector and a SIL20A auto-sampler, Tokyo, Japan). To quantification of the dapsone, the samples were injected $(100 \mu 1)$ with a flow rate of $0.7 \mathrm{ml} \mathrm{min}^{-1}$ and a retention time of 10 minutes using a lichrocart ${ }^{\circledR 250-4}$ and a lichrospher ${ }^{\circledR} 100$ RP-18 (5 $\left.\mu \mathrm{m}\right)$ column. The mobile phase consisted of acetonitrile/water/acetic acid (40:59:1, v/v/v). The dapsone was detected at $293 \mathrm{~nm}$. Our group (21) established the validation of the method for the quantification of dapsone.

\section{Scanning Electron Microscopy (SEM)}

The morphology of powders (DAP-LNC-CS-L1 and DAPLNC-CS-L2) were determined by scanning electron microscope at 10kv (Jeol Scanning Microscope, JSM-6060) in the microscopy and microanalysis center (CMM) of the Federal University of Rio Grande do Sul - UFRGS. Prior to SEM analysis, the powders were put on aluminum stubs 
with carbon double-sided and were sputter-coated with a layer of gold.

\section{Statistical Analyzes}

The statistical analyzes of nanocapsules powders redispersion in different measurement times were evaluated in the software Statistical Analysis System (SAS, USA) using the ANOVA model fixed test with significance level of $\mathrm{p}<0.05$.

\section{Results and discussion}

\section{Development and characterization of the nanocapsule spray-dried powder}

As briefly reported by our group (20), the DAP-LNC-CS suspension presented a unimodal size profile, positive zeta potential, acid $\mathrm{pH}$ and dapsone content close to $100 \%$ (20). The DAP-LNC-CS formulation showed a mean diameter $\left[\mathrm{D}_{4,3}\right]$ of $129 \pm 4 \mathrm{~nm}$ by laser diffraction $(L D)$ and the hydrodynamic mean diameter $\left(\mathrm{d}_{\mathrm{h}}\right)$ was $117 \pm 2 \mathrm{~nm}$ by dynamic light scattering $(D L S)$, whereas polydispersity was $0.88 \pm 0.03$ by $L D$ and polydispersity index $0.14 \pm 0.01$ by $D L S$. The data for the new batch corroborate our previous report for this formulation (20). The chitosan-coated suspension of lipid-core nanocapsules containing dapsone were subjected to the drying process in order to produce a powdery product. For the analytical determination of dapsone in dry samples, the formulations were concentrated to a final volume of $50 \mathrm{~mL}$. The macroscopic analysis of nanocapsules powder acquired using spray-dryer showed a fine white powder with a powdery appearance forming small particles corroborating with literature (21-23).

Size is the most relevant physicochemical property of nanoparticulated systems, such as drug delivery systems (24). In this context, our results demonstrated that the mean diameters $\left(\mathrm{D}_{[4,3]}\right)$ of nanocapsule spray-dried powder ranged from $0.493 \pm 11(\mu \mathrm{m})$ (DAP-LNC-CS-L2) to $0.726 \pm 29$ (DAP-LNC-CS-L1) $(\mu \mathrm{m})$ after 30 minutes of redispersion in water (Table 1). Within the early times of powders dispersion in water, we observed that the mean particle diameters (DAP-LNC-CS-L1 and DAP-LNC-CS-L2) were higher in relation to the subsequent time intervals (Table 1). The laser diffraction curves based on the volume of the particles showed multimodal profiles presenting populations in scales nanometric and micrometric for both formulations (DAP-LNC-CS-L1 and DAP-LNC-CS-L2) (Figure 3 and 4). Additionally, the polydispersity of diameters expressed by SPAN values ranged from $3.23 \pm 112(\mu \mathrm{m})$ (DAP-LNC-CSL2) to $5.00 \pm 251(\mu \mathrm{m})(\mathrm{DAP}-\mathrm{LNC}-\mathrm{CS}-\mathrm{L} 1)$ after 30 minutes of dispersion in water (table 1).

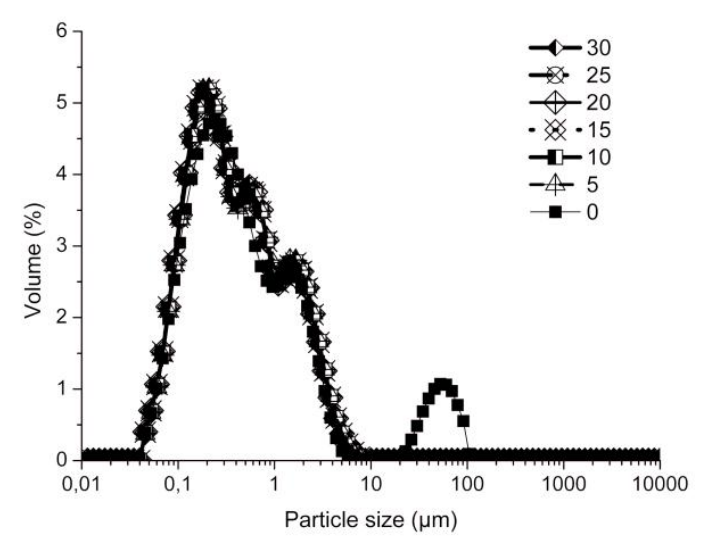

Figure 3: Size distribution curves as a function of time by laser diffraction of DAP-LNC-CS-L1 formulation. Note: 0 to 30 are the time intervals in minutes of sample dispersion in water after addition in the wet unit (Hydro 2000).

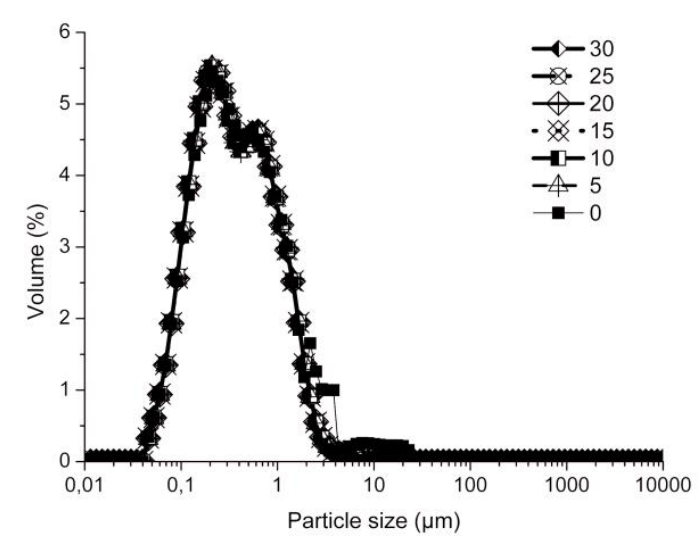

Figure 4: Size distribution curves as a function of time by laser diffraction of DAP-LNC-CS-L2 formulation. Note: 0 to 30 are the time intervals in minutes of sample dispersion in water after addition in the wet unit (Hydro 2000).

In this study, after five minutes of formulations redispersion in water, the mean diameter of DAP-LNC-CS-L1 and DAPLNC-CS-L2 decreased considerably. So to move forward, we use statistical analyzes to demonstrate this phenomenon.

By means of statistical analyzes it showed that there were no significant differences in the redispersion times of the particles between 5 and 30 minutes ( $<<0.05$ ), it means that, in five minutes the powder of the formulations are already redispersed according to the statistical analyzes. After increasing the concentration of leucine, we observed lower mean diameter and polydispersity probably due to the coating of the nanocapsules surface by those molecules decreasing the tendency to form aggregates during the spray-drying process. The presence of chitosan, a polysaccharide, at the particle-water interface might increase the hydrogen bonding increasing the tendency to aggregation. In higher concentration, leucine was able to avoid partially this phenomenon. 
Table 1. Laser diffraction mean diameter and polydispersity as a function of the time of powder dispersion in the wet unit. Formulations

$(\mathrm{n}=3)$

DAP-LNC-CS-L1

DAP-LNC-CS-L2

\begin{tabular}{c|llll}
\hline $\begin{array}{c}\text { Time interval } \\
\text { of records }\end{array}$ & $\mathrm{D}_{[4,3]}(\mu \mathrm{m})$ & SPAN $(\mu \mathrm{m})$ & $\mathrm{D}_{[4,3]}(\mu \mathrm{m})$ & SPAN $(\mu \mathrm{m})$ \\
\hline 0 & $5.156 \pm 371$ & $6.96 \pm 1.113$ & $0.781 \pm 19$ & $3.35 \pm 800$ \\
5 & $0.729 \pm 24$ & $5.18 \pm 198$ & $0.506 \pm 10$ & $3.26 \pm 140$ \\
10 & $0.723 \pm 23$ & $5.18 \pm 220$ & $0.497 \pm 10$ & $3.25 \pm 133$ \\
15 & $0.723 \pm 24$ & $5.14 \pm 261$ & $0.496 \pm 12$ & $3.24 \pm 114$ \\
20 & $0.723 \pm 26$ & $5.10 \pm 267$ & $0.494 \pm 11$ & $3.23 \pm 118$ \\
25 & $0.724 \pm 26$ & $5.04 \pm 247$ & $0.493 \pm 11$ & $3.23 \pm 123$ \\
30 & $0.726 \pm 29$ & $5.00 \pm 251$ & $0.493 \pm 11$ & $3.23 \pm 112$
\end{tabular}

$\mathrm{D}_{[4,3]}$ : volume-weighted mean diameter

SPAN: polydispersity calculated by the difference between the diameters at percentiles 90 and 10, divided by the median diameter (based on the volume of the particles)

According to Marchiori et al., 2011 (25) the particles recovered after redispersion presented similar average sizes compared to the original suspensions. The recoveries of particle diameters after being respread have already been reported in previous studies in nanoparticulate systems $(17,26)$, so both studies were able to recover the particles after their aqueous dispersions. Particle size and high specific surface area provide suitable flow characteristics which are used for the purpose of improving post-dry properties (27). In this context, powders having different granulometries could be administered by means of a dry powder inhaler with an appropriate drug delivery along the respiratory tract (28). The behavior of post-dry redispersion is evaluated by the wet diffraction technique to demonstrate that the powders from a dispersion time are able to recover their nanometric characteristics (29).

\section{Analytical Quantification and Yield of Dapsone in Spray- Powders}

To prove that a drug is administered in a right place in appropriate amount, various analytical methods have been developed to detect and quantify the drugs in the samples $(11,12)$. In this way, the analytical quantification of dapsone in the dry powder samples was determined according to a study reported in the literature and validated in accordance with International Conference on Harmonisation (ICH) (21). The dapsone content in the dry-powders of the nanocapsules formulations presented concentrations ranging from $15.9 \pm$ $0.44 \mathrm{mg} . \mathrm{g}^{-1}$ (DAP-LNC-CS-L2) to $19.8 \pm 0.14 \mathrm{mg} . \mathrm{g}^{-1}$ (DAP-LNC-CS-L1), which represented approximately $92 \pm$ $1.4 \%$ (DAP-LNC-CS-L2) and $95 \pm 0.8 \%$ (DAP-LNC-CS$\mathrm{L} 1)$ of the theoretical content $\left[\left(17.3 \mathrm{mg} . \mathrm{g}^{-1}\right.\right.$ (DAP-LNCCS-L2) and $20.8 \mathrm{mg} . \mathrm{g}^{-1}$ (DAP-LNC-CS-L1), respectively], based on the analytical quantifications of dapsone in the dry powders of nanocapsules by HPLC. The percentage of the quantification of dapsone in the dry powder samples is in agreement with other drugs quantified in the nanoparticle powders $(17,22,23)$. The representative chromatogram of formulations (DAP-LNC-CS-L1 and DAP-LNC-CS-L2), Free-DAP and Blank formulation (LNC-CS-L) are shown in Figure 5.

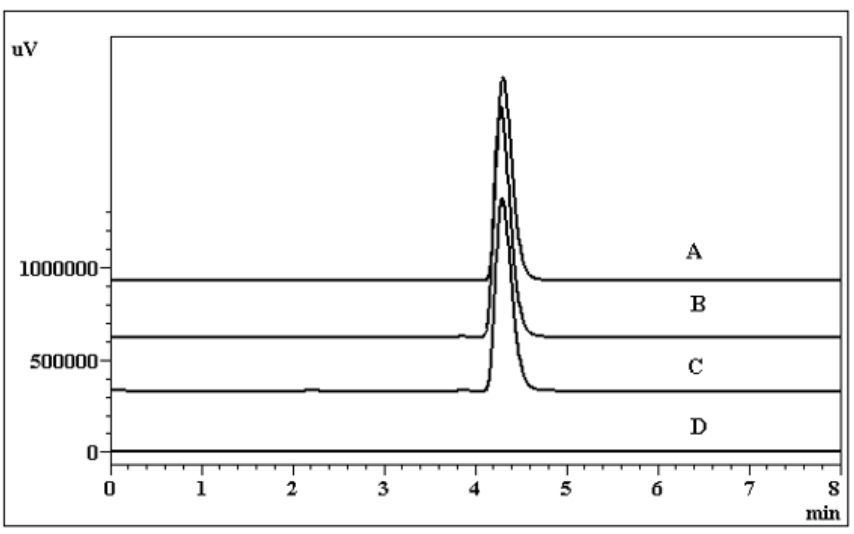

Figure 5: Representative chromatogram of formulations DAPLNC-CS-L1 A), DAP-LNC-CS-L2 B), C) Free-DAP and D) Blank formulation (LNC-CS-L).

The spray-drying process of the lipid-core nanocapsule formulations showed yields ranging from $58 \pm 1.0 \%$ (DAPLNC-CS-L1) to $61 \pm 1.5 \%$ (DAP-LNC-CS-L2). Additionally, the water loss after desiccation was below $2 \%$ [(DAP-LNC-CS-L2 - $1.30 \pm 0.3 \%$ ), (DAP-LNC-CS-L1 $1.33 \pm 0.2 \%$ ] indicating the efficiency of the drying process to remove water from the system. Powders prepared with adjuvants promote a better yield of the process, which is essential to maintain its properties and thus to become a good candidate for the treatment of diseases $(14,17,23,24)$.

Our data showed that there were no significant losses of drug during the drying process. Marchiori et al., 2011 (25) obtained a $95 \%$ content after drying the lipid nanocapsules of the lipid core containing tretinoin, which is a drug that undergoes photodegradation by ultraviolet light. Besides, another study reported that dry powders of lipid core nanocapsules containing tretinoin significantly improved the photostability of tretinoin compared to the formulation containing the unencapsulated drug (30).

\section{Scanning Electron Microscopy of the nanocapsule spray- dried powder}

The scanning electron microscopy (SEM) images obtained from the formulations DAP-LNC-CS-L1 and DAP-LNCCS-L2 showed the presence of morphological agglomerates and an irregular surface of the particles according to Figure 6. The SEM images found in our study corroborate with other dry powder images of spray-dried nanocapsules obtained by SEM $(22,23,28)$. 


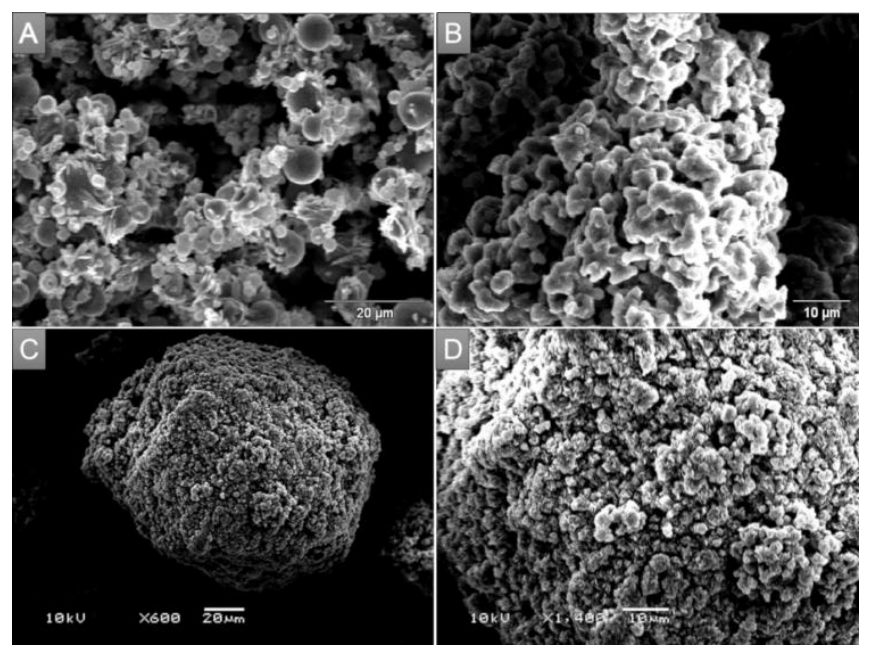

Figure 6: Scanning electron microscopy (SEM) of the nanocapsules spray-dried powders: DAP-LNC-CS-L1 [(A) bar = $20 \mu \mathrm{m}$ and $(\mathrm{B}) \mathrm{bar}=10 \mu \mathrm{m}]$, and DAP-LNC-CS-L2 [(C) bar $=20$ $\mu \mathrm{m}$ and (D) bar $=10 \mu \mathrm{m}]$.

\section{Conclusion}

Our results indicated that spray drying of the lipid core nanocapsules formulations prepared with dapsone and leucine (DAP-LNC-CS-L1 and DAP-LNC-CS-L2) exhibited an efficient aqueous dispersion of nanocapsule powders. The analytical quantification of dapsone in spray dried-powders revealed that the content of dapsone was higher than $92 \%$ in the powders. In this context, we have shown that the drying process for determination of dapsone analysis in spraypowders nanocapsules is a viable and efficient tool.

\section{Acknowledgements}

This study was supported by CAPES, CNPq, and FAPERGS (Brazil). "This study was financed in part by the Coordenação de Aperfeiçoamento de Pessoal de Nível Superior - Brasil (CAPES) - Finance Code 001".

\section{References}

1. Wozel, G.; Blasum, C. Dapsone in dermatology and beyond. Arch Dermatol Res. 2014; 306;103124.

2. Ahmad, R.A.; Rogers, H.J. Pharmacokinetics and Protein Binding Interactions of Dapsone and Pyrimethamine. Br. J. clin. Pharmac. 1980;10:519524.

3. Zuidema, J.; Hilbers-Modderman, E.S.M.; Merkus, F. W. H. M. Clinical Pharmacokinetics of Dapsone. Clinical Pharmacokinetics. 1986;11:299-315.

4. Vukovic', G.D.; Tomic', S. Z.; Marinkovic', A. D.; Radmilovic', V.; Uskokovic', P. S.; Colic', M. The response of peritoneal macrophages to dapsone covalently attached on the surface of carbon nanotubes. CARBON. 2010; 48:3066-1078.
5. Kumar, M. N. V. R. A review of chitin and chitosan applications. Reactive \& Functional Polymers. 2000;46:1-27.

6. Gavhane, Y. N.; Gurav, A. S.; Yadav, A.V. Chitosan and Its Applications: A Review of Literature. International Journal of Research in Pharmaceutical and Biomedical Sciences. 2013;4:312-331.

7. Vehring, R.; Foss, W. R.; Lechuga-Ballesteros, D. Particle formation in spray drying. Aerosol Science. 2007;38:728-746.

8. Jain, M.S.; Lohare, G.B.; Bari, M.M.; Chavan, R.B.; Barhate, S.D.; Shah, C. B. Spray Drying in Pharmaceutical Industry: A Review. Research J. Pharma. Dosage Forms and Tech. 2011;2:74-79.

9. Audhia, C.J.; Raval, J.A.; Patel, M.M.; Shah, N.V.; Chauhan, S.P.; Sailor, G.U.; Javia, A.R.; Mahaswari, R.A. Spray Drying in the Pharmaceutical Industry - A Review. Indo American Journal of Pharmaceutical Research. 2011;2:125-138.

10. Sollohub, K.; Cal, K. Spray Drying Technique: II. Current Applications in Pharmaceutical Technology. Journal of Pharmaceutical Sciences. 2010;99:587-597.

11. Consortti, L.P; Salgado, H.R.N. A critical review of analytical methods for quantification of cefotaxime, Critical Reviews in Analytical Chemistry. 2017:47: 359-371.

12. Siddiqui, M. R; Othman, Z.A; Rahman, N. Analytical techniques in pharmaceutical analysis: A review. Arabian Journal of Chemistry, 2017:10:S1409-S1421.

13. United States Pharmacopoeia, 1980. 20th ed. The USP Convention Inc., Rockville, MD.

14. Muller, C.R.; Bassani, V.L.; Pohlmann, A.R.; Michalowski, C.B.; P.R. Petrovick, P.R.; Guterres, S.S. Preparation and Characterization of SprayDried Polymeric Nanocapsules. Drug Development and Industrial Pharmacy. 2000;26:343-347.

15. Hoffmeister, C.R.D.; Durli, T.L.; Schaffazick, S.R.; Raffin, R.P.; Bender, E.A.; Beck, R.C.R.; Pohlmann, A.R.; Guterres, S.S. Hydrogels containing redispersible spray-dried melatoninloaded nanocapsules: a formulation for transdermal-controlled delivery. Nanoscale Research Letters. 2012;7:251.

16. Raffin, R.P.; Jornada, D.S.; Ré, M.I.; Pohlmann, A.R.; Guterres, S.S. Sodium pantoprazole-loaded enteric microparticles prepared by spray drying: effect of the scale of production and process 
validation. International Journal of Pharmaceutics. 2006;324:10-18.

17. Beck, R.C.R.; Lionzo, M.I.Z.; Costa, T.M.H.; Benvenutti, E.V.; Ré, M.I.; Gallas, M.R.; Pohlmann, A.R.; Guterres, S.S. Surface morphology of spray-dried nanoparticle coated microparticles designed as an oral drug delivery system. Brazilian Journal of Chemical Engineering. 2008;25:389-398.

18. Tewa-Tagne, P.; Briancon, S.; Fessi, H. Preparation of redispersible dry nanocapsules by means of spray-drying: development and characterisation. European Journal of Pharmaceutical Sciences, 2007;30:124-135.

19. Aquino, R.P.; Prota, L.; Auriemma, G.; Santoro, A.; Mencherini, T.; Colombo, G. Dry powder inhalers of gentamicin and leucine: formulation parameters, aerosol performance and in vitro toxicity on cufi1 cells. Int J Pharm. 2012;426:1007.

20. Cé, R.; Marchi, J.G; Bergamo, V.Z; Fuentefria, A.M; Lavayen, V; Guterres, S.S; Pohlmann, A.R. Chitosan-coated dapsone-loaded lipid-core nanocapsules: Growthinhibition of clinical isolates, multidrug-resistant Staphylococcusaureus and Aspergillus ssp. Colloids and Surfaces A: Physicochem. Eng. Aspects. 2016;511:153-161.

21. Ortiz, M.; Jornada, D.S.; Pohlmann, A.R.; Guterres, S.S. Development of Novel Chitosan Microcapsules for Pulmonary Delivery of Dapsone: Characterization, Aerosol Performance, and In Vivo Toxicity Evaluation. AAPS PharmSciTech. 2015;02.

22. Zuglianello, C.; De Andrade, D. F.; Chaves, P. S.; Rigo, L. A.; Pohlmann, A. R.; Guterres, S. S.; Beck, R. C. R. Redispersible spray-dried nanocapsules for the development of skin delivery systems: proposing a novel blend of drying adjuvants, Soft Materials. 2018:16:20-30.

23. De Oliveira, E. G.; Cardoso, A. M.; Paese, K.; Coradini, K.; De Oliveira, C. V.; Pohlmann, A. R.; Oliveira, M. S.; Guterres, S.S.; Beck, R. C. R. Reconstituted spray-dried phenytoin-loaded nanocapsules improve the in vivo phenytoin anticonvulsant effect and the survival time in mice, International Journal of Pharmaceutics. 2018:551:121-132.

24. Pohlmann, A.R., Detoni, C.B., Paese, K., Coradini, K., Beck, R.C.R., and Guterres, S.S. (2016) Polymeric nanocapsules for topical delivery. In Percutaneous Penetration Enhancers Chemical Methods in Penetration Enhancement, 201-221; Dragicevic, N, and Hi, Meditors; Heidelberg,
Germany:

Springer.

25. Marchiori, M.C.L.; Ourique, A.F.; Silva, C.B.; Raffin, R.P.; Pohlmann, A.R.; Guterres, S.S.; Beck, R.C.R. Spray-Dried Powders Containing TretinoinLoaded Engineered Lipid-Core Nanocapsules: Development and Photostability Study. Journal of Nanoscience and Nanotechnology. 2011;11:1-9.

26. Domingues, G.S.; Guterres, S.S.; Beck, R.C.R.; Pohlmann, A.R. Micropartículas nanorrevestidas contendo umfármaco modelo hidrofóbico: preparação emetapa única e caracterização biofarmacêutica. Quim. Nova. 2008;31:1966-1972.

27. Rowe, R. C.; Sheskey, P. J.; Weller, P. J. Handbook of Pharmaceutical Excipients, 4th ed. Pharmaceutical, London, 2003.

28. Zatta, K.C.; Frank, L.A.; Reolon, L.A.; AmaralMachado, L.; Egito, E.S.T.; Gremião, M. P. D.; Pohlmann, A. R.; Guterres, S. S. An Inhalable Powder Formulation Based on Microand Nanoparticles Containing 5-Fluorouracil for the Treatment of Metastatic Melanoma. Nanomaterials. 2018;8:1-21

29. Ourique, A.F.; Chaves, P.S.; Souto, G.D.; Pohlmann, A.R.; Guterres, S.S.; Beck, R.C.R. Redispersible liposomal-N-acetylcysteine powder for pulmonary administration: Development, in vitro characterization and antioxidant activity. European Journal of Pharmaceutical Sciences. 2014;65:174-182.

30. Marchiori, M.C.; Rascovetzki, R.H.; Ourique, A.F.; Rigo, L.A.; Silva, C.B.; Beck, R.C. Improved tretinoin photostability in a topical nanomedicine replacing original liquid suspension with spraydried powder with no loss of effectiveness. Drug Dev Ind Pharm. 2013;4:579-586. 